\title{
Synergies of Advanced Technologies and Role of VANET in Logistics and Transportation
}

Amir Qayyum

CoReNeT,

Capital University of Science and

Technology (CUST), Islamabad, Pakistan

\author{
Kishwer Abdul Khaliq \\ IGS,University of Bremen, Germany
}

Department of Production Engineering,

Abstract-In Intelligent Transport Systems (ITS), Vehicular Ad-hoc Network (VANET) is one of key wireless technologies, which helps in managing road safety, traffic efficiency, fleet, logistics and transportation. The objective of this paper is to give an overview of the implication of different technologies and placement of VANET in transportation and specifically in logistics. We provide researchers with an overview of considered technologies in logistics scenarios and the current projects regarding VANET for safety and non-safety applications. We additionally discuss current and potential domains in logistics in which new applications can improve efficiency by use of new and existing technologies.
\end{abstract}

Keywords-VANET; IEEE802.11p; Logistics; Vehicular Ad-hoc Network; Transportation; Technology role

\section{INTRODUCTION}

In project of the European commission (EC) named "Mobility and Transport", Intelligent Transport Systems (ITS) [1] is one of the transport topics which deals with the traffic management, safety and efficiency among many target transport mode. To get improvement in transportation system, it applies information and communication technologies like computers, electronics, satellites and sensors. These technological possibilities require us to rethink design, implementation and deployment of existing technologies in different transport modes like road, air, water, and rail to provide new services for passengers and freight transport [2]. Therefore, the first goal of ITS is to manage transport systems and the second goal is to render the transport network more safe. In case of the traffic congestion, it aims to reduce both the traffic and also its impact on the environment. Hence, efficiency is the third goal of ITS. To achieve the goal of traffic management, safety, and efficiency, a number of communication technologies are involved in ITS, e.g., ITS-G5 [3], Wi-Fi [4], 3G [5], LTE [6] etc. to create innovative solutions. The linkage between the EC project, ITS and technologies is shown in Figure 1. Several technologies have been deployed to maintain and promote ITS. Logistics companies focus on the flexibility and efficiency to save time and labor cost. Thus, the improvement of the transportation system and communicating interfaces of these companies contributes to achieve the goals [7].

Vehicular Ad-hoc Network is the one of the challenging domains in wireless networks and has unique features. It does not only offer efficient traffic management, logistics and transportation, navigation, and road safety applications, but also regards for online gaming and infotainment applications [8].

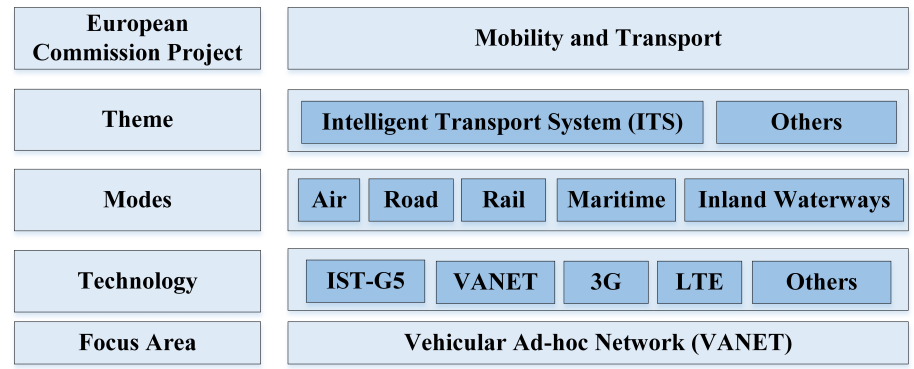

Fig. 1: Intelligent Transport System (ITS) and Underlying Technologies
Logistics include a number of activities that ensure the timely availability of the right product to the customer and these activities create a bridge between production and consumption [9]. Consequently, it links the production and market locations. Two parameters can have great impact on the distance between production plant to the location market or supplier unit, i.e. availability of the product to deliver, and time efficiency in delivery of it. To get market benefits, delivery of the right product to the right consumer on right time is equally important for all companies. These two requirements have changed the procedure of production and delivery. To cope with this challenge, the sub-system of logistic requires efficiency and automation. Figure 2 shows the logistics process, where each stage has specific requirements with respect to the next level. At each level different technologies are in use to get the required benefits. Regarding raw material, the efficient collection of it can boost the production of the desired product. At the production units, synchronization of production steps autonomously and information management about the product specification according to demand are the important factors. Latest technologies like robotics, WiFi, multi-agent system and others help to increase productivity and improve management systems. Market share increases with the best distribution of product in the market and simple accessibility for the customer. Online technologies play an important role not only for the product advertisement, but also for purchasing.

Each company promotes its product as a best product in the market. A new product progresses through a sequence of stages called product life cycle from introduction to growth, maturity, and decline. The success of the production cycle depends upon type of product, knowledge of production, people and 
knowledge of people's requirements. In order to increase the value of the product, different services are added to the product by converting raw-materials into the customized products. Therefore, the production cycle includes many values into it. For example form-value is added to the product by converting the raw-materials into finished product during production and manufacturing, place-value is provided through transportation by moving the finished products to the needed location, and time-value is provided through storage and inventory controls to ensure the availability of the products when needed. Finally, possession-value is added to the product through marketing and sales. In this whole procedure, place and time-values are the key logistics functions.

To meet the challenge of product-delivery from the production-unit to the market, efficiency in transportation is required. Efficiency in terms of time may vary because it depends on the type of product, mode of transport and location of the need [10]-[12]. The development of technology like automobiles, electronic devices, home appliances require different place and time-values than the production of food items. The food-item exhibits a short life span and requires delivery to market when it is fresh. In a competitive market, the latest technologies are used to shorten the process of production, and enhance storage and inventory for the quick distribution, monitoring and possible re-routing. Sourcing from

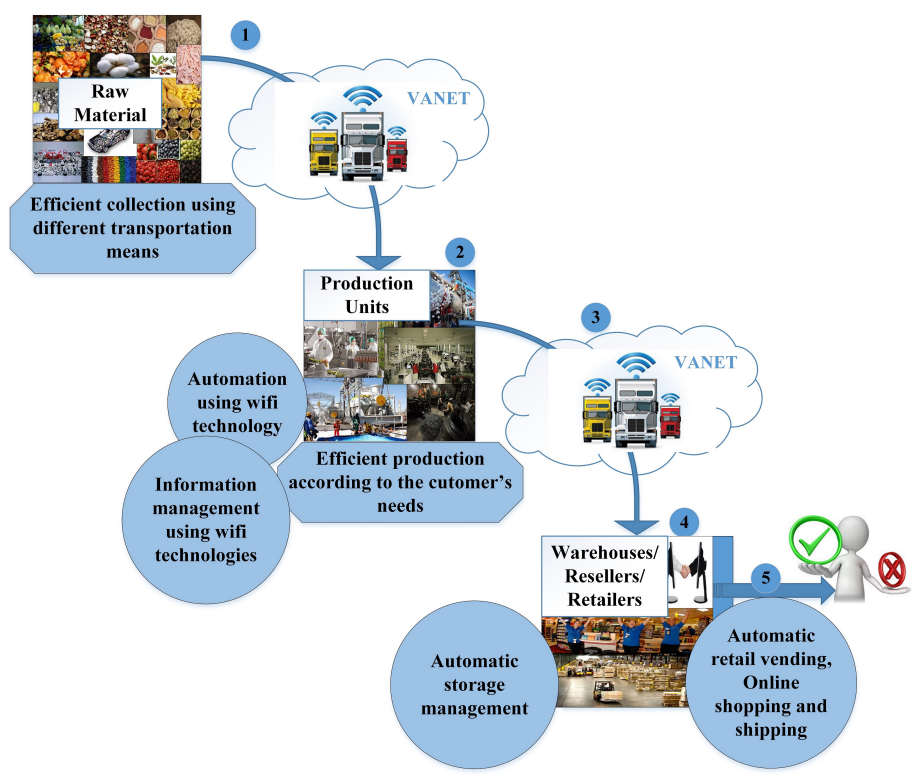

Fig. 2: Possible Placement of Technologies in Logistics and Transportation

the raw material to the finished products and the respective distribution involves many tiers in the supply chain flow. In practice, supply chain integration is the set screw and also active research area to improve the supply chain performance. Basically, this integration involves two kinds of flows. The first flow involves the physical steps that need to be carried out, while the second flow complements the first flow (logistics) with respective information. Previous studies [13][15] addressed these two flows by merging information and logistics. The research studies also showed that with the help of technology transference [16]-[18] and new technologies integration e.g., RFID [19], robotics [20], [21], WiFi and communication technologies [22]-[25] etc., the process of logistics and transportation has become more flexible. The objective of this paper is to pinpoint the advantages of existing technologies and importance of VANET technology in logistics and transportation with respect to the previously mentioned issues, and to discuss use of multiple technologies together to a get solution for complex processes. The use of technologies aims to simplify this process by reducing time of product life cycle with value added services and reducing delay while delivering products.

The rest of the paper is organized as follows. Section III gives the state of the art. It reviews the technology role in logistics and transportation, explains different technologies in context of different sub-problems and challenges in the scenario of logistics and transportation, and also discusses VANET current projects in the research area. Section III discusses different scenarios where one or more technologies can add benefits to companies. It also describes applications of different technologies for logistics and transportation. Section IV concludes and explains possible future work.

\section{AdVANCED TECHNOLOGIES IN LOGISTICS}

The efficient production of customized products and their supply are the key to success for many companies. Failure leads to loss of revenue, decline in level of services, reputation and market share. Recent developments in the market e.g. increase in market competition along number of products with short life cycle and product proliferation, have created a scenario where the customer's demands are unpredictable. Thus, the ability to appropriately respond to the market has become a major asset for many companies, and a motivation for improving their logistics systems [26].

The last few decades, the business environment has changed due to advances in information technologies in extracting, manufacturing and servicing industries. In addition to these, the positive growth of knowledge industry [27] [28] has raised productivity by generating more worker autonomy or greater managerial control. This change is particularly visible in the European Union. Many small and medium size companies have logistic management at their high priority to gain competitive benefits [29], [30]. From point of origin to the point of destination, logistics includes planning, implementing, controlling, transportation of goods, services and related information [31]. The reverse logistics system planning [32] is beneficial for home appliances and proposed a mixed integer programming model to determine the optimal configuration. This model used return rates to determine the numbers, storage locations and plants and showed the benefits of sharing facilities in recycling electrical appliances and computers [33]. To obtain an efficient and flexible system start-to-end, different technologies can be used for sub-tasks. Figure 4 divides the logistics tasks and sub-functions. In each sub-function, integration of particular technology offers added values for the efficient execution and best end results. Each technology plays a vital role to solve sub-functions of logistics to earn revenue. 


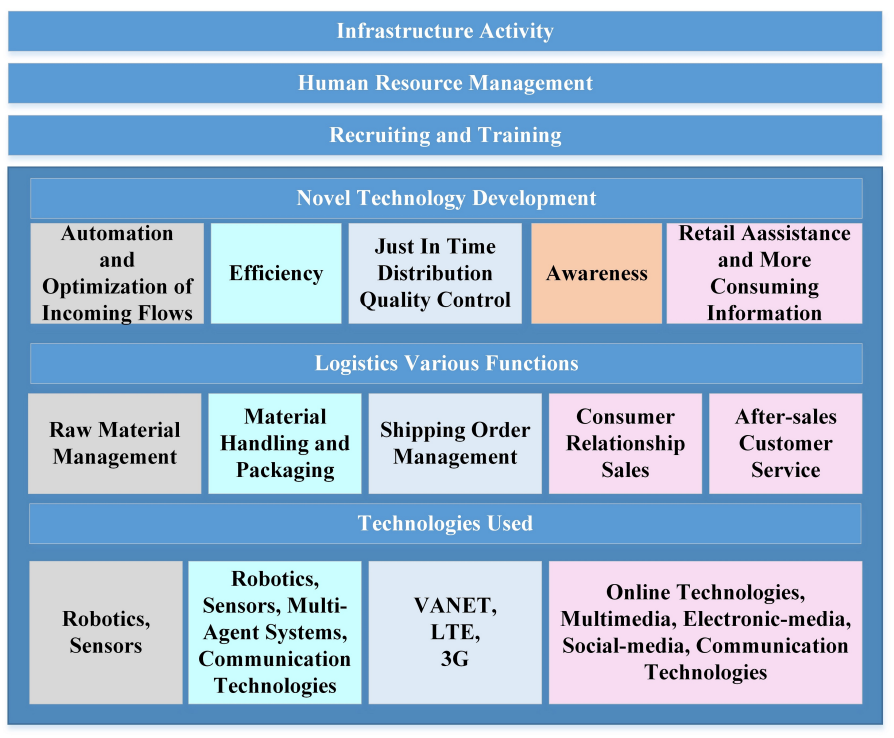

Fig. 3: Logistics Process with Integration of Technologies

\section{A. Multi-Agent Systems}

Logistics and supply chain systems consist of number of sub-system that can communicate with one another autonomously to maximize utility. Considering their complex relationship and decision making processes of these sub-system, a multi-agent system modeling is a suitable approach. It is used for the convenient modeling of these sub-systems [34] to improve efficiency of supply chain, solve dynamic logistic management, food supply chain management, fleet management, mass customisation issues and make profit through ecommerce.

To improve the efficiency of the food supply chain, the authors of [29] introduced an agent technology model and resulting food supply chain includes the new feature of intelligence, which allows to optimize performance of the system. They described two ways for optimization: firstly, they reviewed intelligent agents applications, analyzed and compared the existing technologies, then critically reviewed the integration of agent technology in the supply chain management. Secondly, they explained the multi-agent system and its mechanism of optimization to solve many tasks like inventory issues, bullwhip effect, communication problem or adverse risk sharing. Furthermore, it offers a capability to purchase and sale while in transit. In [21], the authors discussed the convenience of automatic systems for loading and unloading with the increase of the number of parcels. This automation can offer benefits to logistics companies by reducing the cost of labor and consumption of time.

To solve the problem of dynamic logistic process management, a real-time knowledge-based framework has proposed in [35] with the use of RFID-multi-agents. The system is capable of real-time process management" which has functionality to identify current process status, perform checking/reasoning, and support to staff members by providing knowledge about the process while handling logistics activity problems. It included an application case study of Eastern Worldwide
Company Limited to reveal the performance of operations and resources utilization significantly.

The authors in paper [36] discuss multi-agent system for the case study of e-commerce. Here, for the design of the logistics, delivery of products, their storage and transportation, a third party logistics (3PL) takes responsibility in a supply chain. A 3PL vendor used multi-agent system to build up a private logistics service unit and virtual private logistics subsystem (VPL). By this way, they integrated own logistics business process with the supply chain members. In the supply chain, the logistics and its information flow are seamlessly connected with the financing and trading flows. The 3PL vendor would keep the stability of its own business process while providing customized services to the supply chain members.

The resource allocation problem is usually solved, when system has real time information of all the orders and resources in advance and it does not affect the process of scheduling. On the basis of real time analysis, it is concluded that intelligent applications help to cover mentioned problem in domain of transport system including traffic issues. These intelligent systems include multi-agent simulation platform for traffic modeling, decision support systems for letter transportation, logistics planning, sea freight transportation, vehicle dispatching, scheduling for railway and truck transportation and others [37]-[42] [43].

In [41], authors defined mass customization as a transition process of individualization of mass-market goods and services which are used to fulfill particular customer needs at an affordable and reasonable price. They discussed the lack of flexibility in conventional enterprise resource planning and supply chain management systems to cope with the new requirements of market. To overcome these drawbacks, multi-agent systems are used to provide suitable means and also presented a solution to handle customization and corresponding information logistics in flexible way and to extend inter-business relations by partial automatic management.

In [44], the authors discussed the cost reduction and complex optimization problem for dispatching and planning scheduling of freight in a highly competitive market with an increasing share for general cargo. To minimize the complexity in such scenario, an autonomous coordination of transport services and planning processes can help. The paper introduced a multi-agent based approach that solved mentioned issues by enabling an autonomous dispatch process in mentioned scenario and also tackled resource allocation problems. Additionally, it supports a human dispatch manager in decision by developing a Decision-Support System (DSS). The responsibility of DSS is to provide proposals for allocations of transport orders to trucks. Table I] discusses the role of multi-agent systems for the sub-functions of logistics with the proposed solution. Different multi-agent systems are proposed to solve different issues like optimization in the food supply chain, automation problem for loading-unloading, e-commerce solution for customised services, resource allocation problem, mass-customization, information management issue and to reduce cost and complex optimization. 
TABLE I: Multi-Agent Systems in Logistics

\begin{tabular}{|c|c|c|}
\hline Article & Targeted Problem & Solution \\
\hline 29 & Optimization problem in food supply chain & $\begin{array}{l}\text { Agent technology model to optimize multiple tasks like bullwhip effect, inventor and } \\
\text { communication issues }\end{array}$ \\
\hline$[21]$ & Automation problem for loading and unloading & Automatic system to reduce cost of labor and consumption time \\
\hline 36 & E-commerce for supply chain & $\begin{array}{l}\text { Multi-agent system for an e-commerce environment to keep the stability of its own business } \\
\text { process while providing customized services to the supply chain members }\end{array}$ \\
\hline [37], [38], [40]-42] & Resource allocation problem & $\begin{array}{l}\text { Multi-agent system for traffic modeling, decision support system, logistic planning and } \\
\text { transportation scheduling }\end{array}$ \\
\hline 41 & $\begin{array}{l}\text { Mass customization and information management } \\
\text { issue }\end{array}$ & $\begin{array}{l}\text { Co-operative multi-agent system to handle mass customization and extend inter-business } \\
\text { relationship }\end{array}$ \\
\hline $44,, 45$ & Cost reduction and complex optimization problem & $\begin{array}{l}\text { Multi-agent mechanism of autonomous coordination of transport services for dispatching } \\
\text { and planning scheduling }\end{array}$ \\
\hline
\end{tabular}

\section{B. Robotics}

In order to optimize internal material flow, the requirement and demand of industrial robot-technologies is increasing. The use of robotics and other technologies in logistics is common and research institutes (like Massachusetts Institute of Technology, the Bremen Institute of Production and Logistics (BIBA), the Institute of Shipping Economics and Logistics (ISL), London Business School, etc. ) are trying to integrate different technologies in logistics. In [20], authors classified roboticslogistics activities in many scenarios such as loading/unloading and palletizing/depalletizing of goods, and discussed possible scenarios for research and development activities. Companies are trying to enhance functionality and flexibility of working in production units by means of robotics.

In [46] the authors discussed introduction of robots in industry. The idea was initially to use it for production of components of industrialized building and modular housing. In earlier Seventeenth century, first robots had been designed for construction and at the end the century, construction site had been developed. In Japan, it had been used to improve quality in prefabrication of modular homes. In addition to it, maintenance and safety robots had been developed for cleaning, inspection and safety. Furthermore, humanoid robots for construction are already tested, but service robots are in planning to build environment in future.

Nowadays, mobile robotics are significantly used not only for commercially and personally, but also for education and research due to offered new application [47]. An autonomous mobile mechatronic system for learning and research has been introduced by company Festo Didactic. This system is named as Robotino [48] and also introduced as standardized platform for education in the area of engineering and information technology. In [49], the authors discussed the impact of Robotino. They argued that this system provides an easy methods for education and also creates enabling environment to the industrially-relevant engineers for practical training.

Autonomous robots contain a software component and perform task-level executions depending upon the instructions for a certain goal. Planning in this case is still an exception rather than the norm because domains are often too dynamic or complex. In [50], authors characterized the RoboCup Logistics League (RCLL) as a medium complex robotics planning domain considering properties, implementation strategies, and planning models and also proposed a RCLL testbed as a benchmark for comparison.

In e-commerce, logistics requires attention to handle prob- lems such as delays in deliveries or wrong deliveries, packages lost while shipping or damaging goods due to improper packing or handling. Automation helps to improve efficiency of storage and retrieval system. Furthermore, it extends their capacities and capabilities through autonomous storage and retrieval system (ASRS. But it has limitation of flexibility due to variant properties of order. In order to get a balance between efficiency, scalability and flexibility, the use of robotics is vital. In [51], the authors discussed the use of mobile robots in industrial developments. These are in being used to achieve robotic picking methods and extended the Product Service System (PSS) where the prime goal is to focus core competencies using a Logistics Automation Service System (LASS) business model.

Table II discusses the problems of loading/unloading, palletizing/depalletizing, construction, education and research methods and training, planning system defects and e-commerce logistics bottle-neck and also lists the possible solution for the mentioned problems using robotics to get economical benefits by reducing labour cost, time and improving efficiency.

C. Online Technologies

In the era of Internet, customers migrated into the online world, therefore Internet marketers use emails to collect and organize data for potential prospects. Email becomes a primary way among many business marketers to connect with customers. With the emerging of e-commerce on the Internet, a new form of marketing has evolved. Online marketers use different strategies to get attention of their customers from online banners to pop ups. Classically, technical marketing focused on the design of product with the specifications and key features, but at the same time designed to appeal to customers with basic information of product. However, it has also grown marketing strategies to encompass any use of modern technology as a marketing tool. Considering a case of a software company, which offers Adobe Systems having worth billions of dollars. A wide range of products are offered by this system. A number of companies rely on it and ts potential customers are basically skilled, highly computer literate professionals. The use of this product is a marketing tool for marketers.

The paper [52] addressed the effective use of Information Technology (IT) capabilities and the synchronous online technology in education section. In a teaching, learning and developing environment of an institute, it presented a theoretical model considering key capabilities of IT and synchronous online technology to support the large scale deployment, e.g., Black-board Collaborate. Apart from the education sector, 
TABLE II: Robotics in Logistics

\begin{tabular}{|l|l|l|}
\hline Article & Targeted sub-task & Solution \\
\hline$[20]$ & $\begin{array}{l}\text { Loading/unloading and palletizing/depalletizing of } \\
\text { goods }\end{array}$ & Automation using robotics for economical efficiency and flexibility \\
\hline & Construction & $\begin{array}{l}\text { Construction robots to increase quality in prefabrication of home, maintenance and safety } \\
\text { robots had been developed for cleaning, inspection and safety }\end{array}$ \\
\hline & Education and research & Standardized platform for education in engineering and information technology \\
\hline 450$]$ & Planning Systems for logistics & $\begin{array}{l}\text { Proposed a RCLL testbed as a benchmark for comparison of planning systems } \\
\text { flexibility }\end{array}$ \\
\hline & E-commerce logistics issues &
\end{tabular}

TABLE III: Online Technologies in Logistics

\begin{tabular}{|c|c|c|}
\hline Article & Targeted Sub-area & Solution \\
\hline$[52]$ & Teaching and Learning & $\begin{array}{l}\text { Theoretical model on basis of key IT capabilities and synchronous online technology to } \\
\text { support for deployment on large scale }\end{array}$ \\
\hline [53] [54] & Online-shopping behaviours & Analysis of shopping trend and identification of customer need from online data collect \\
\hline$[55]$ & Advertisement and Marketing & Technical marketing using enabling online/computer technologies \\
\hline$[56[57$ & E-commerce & Online shopping \\
\hline
\end{tabular}

these online technologies are also used to observe the general online shopping behavior and particular on gender or cultural base behaviour [53] [54]. In competitive business environment where we have a number of providers, the key point in the hand of organizations is to understand the desires and needs of their customers. These online technologies help to analyze the trend of customer behaviour and adopt new policies for their product according to customer need and desire.

\section{Wireless Communication Technologies}

The article [22] showed the importance of construction supply chain management (CSCM) and how its is helpful. Construction projects are complex and big in size, e.g., high rised buildings or mega-sized buildings. Usually, on the construction site, there is little storage space, but high demand of construction components and materials. Hence, for the success, efficient and optimized supply chain management is required. In-spite of the availability of research and development of radio frequency identification (RFID), the mobile devices are still required to carry to check logistic flow in supply chain process. However, by the use of RFID and Wireless Sensor Networksbased operations, the equipment can become main drive for the whole process and may include movers, trailers, gates, and hoists. Another article [23] discussed the use of Wireless Mesh Network (WMN) for logistics and Wireless Sensor Network (WSN) to control and manage the logistic flow. The enlisted activities are the logistic functions of handling, packaging and distribution.

\section{E. Internet of Things (IoT)}

Internet of Things (IoT) is enabling technology and researchers are focusing on enabling the material procurement process improvement of a manufacturer by using it. IoT and Cloud Manufacturing (CM) are linked technologies, are practically inadequate, particularly for a highly service-driven manufacturing execution system. In this system CM supports to respond in capturing the IoT-enabled execution hierarchy dynamically [58]. In the supply chain network, the One Stop Logistic Service Provider (1SLP) is an integrator, which is used to design and implement comprehensive solutions for logistic service by assembling the resources, capabilities, and integrated technologies of supply chain networks. In [59], authors developed the IoT enabled 1SLP process to reduce excessive operation times and integrate with the network information. The authors in [60] proposed a novel multilayered vehicular data cloud platform. This platform is designed by using cloud computing and IoT technologies and used for warranty analysis of vehicles in the IoT environment. IoT can provide a good backbone support for ITS, however this area is not mature yet.

The IoT could also contribute significantly in the food and agribusiness industry. In food supply, perishable products have unpredictable supply variations and mean time they require food safety and sustainability. In this scenario IoT are used to solve these issue because it allows for remotely controlling the location, conditions of shipments and products. In [61], authors also developed a reference architecture using IoT for logistic information systems where it supported the provision of affordable tailor-made solutions.

Apart from the production, handling and safety of machinery and material is also important. For material handling, authors in [62] explained material handling system via analysis and performance availability in regard to energy-harvesting, ultra-low-power devices. They also discussed details of the hardware platform including architecture and testbed. They paid particular attention to the inBin smart device and energyharvesting in the mentioned system. For the safety, the authors in [63] developed a monitoring system, particularly focusing for the type of cranes used to hoist heavy loads in the open air environment with the help of IoT. The latter included both hardware unit and software, and applied in engineering.

\section{F. VANET}

In case of disaster areas, an important task is to manage the resources via restoring the information flow to help in the recovery process. VANET is a wireless technology that is deployed in such disaster areas to recover the communication link [64] [65]. Communication among vehicles is discussed in [25] and authors presented the concept of car-2-car communication as 'smart object' and aimed to increase driving with comfort and safety. This communication should be secure and 
TABLE IV: Communication Technologies in Logistics

\begin{tabular}{|r|l|l|}
\hline Article & Targeted Sub-task & Solution \\
\hline 58 & Synchronization issue & A real-time production logistics synchronization system \\
\hline 59 & Operation time and information flow & $\begin{array}{l}\text { IoT enabled 1SLP process to reduce excessive operation times and integrate with the } \\
\text { network information }\end{array}$ \\
\hline 61 & $\begin{array}{l}\text { Reference architecture for IoT-based logistic information systems where it supported the } \\
\text { provision of affordable tailor-made solutions }\end{array}$ \\
\hline 62 & Material handling & $\begin{array}{l}\text { Material handling systems in regard to energy-harvesting, ultra-low-power devices } \\
\text { system }\end{array}$ \\
\hline 63 & Safety and monitoring &
\end{tabular}

confidential [66]. The article [24] discussed its support for applications that notify about route hazards and incidents to both the drivers and logistics coordinators. Apart from the ITS usage, VANET applications includes a number of scenarios, such as information dissemination for safety like emergency alerts, traffic condition, service messages, road jam due to accidents, and collision avoidance. The disseminated information can be used for fleet coordination or rerouting of vehicles [67], but also for advertisements (e.g. disseminate marketing data), multimedia content distribution (e.g. audio, video streaming) [68], [69], [70] and environmental monitoring networks to gather information data (e.g. pollution, traffic monitoring and road pavement defects) [71]. For future services, the expansion of the smart grid represents a unique challenge in terms of the convergence of network platforms. WiFi as VANETs have the potential to become a reliable wireless network platform to support both the requirements of the smart grid and ITS-based services. Logistics companies are required to have flexible and cost efficient system to monitor, control and deliver products on time. The customers are also interested to have hassle free dealing with the logistics companies. In all these cases, multihop wireless broadcast is an important component in vehicular networks because network properties allows to exploit this feature. VANET is a good choice to fit in these scenarios due to its unique characteristics, low cost and simple deployment.

In port scenarios,complexity is increasing with the expansion of supply chains. Modern ports require advanced track and trace, security, information sharing and monitoring and VANET has the potential to fulfill these needs of port facilities [72] [73]. In [74], authors discussed the adoption of communication technologies to experience high levels of visibility, control and connectivity across the entire supply chain and examined the feasibility of VANET in a multimodal logistics environment. They recommended architecture to provide mentioned goals, which also assure security while accessing. An other article [75] explained its potential to manage the flow of goods and resources efficiently, particularly within international ports. In [76] authors discussed the key role of Information and Communication Technology (ICT in managing logistics operations and supply chains. Table $\mathrm{V}$ summarizes this discussion along target sub-tasks and solutions provided by the mentioned technology.

\section{VANET PROJECTS, APPLICATIONS AND Discussion}

Under the European Commission, a wide variety of projects for transportation is currently underway. Intelligent Transport System (ITS) [77] aims to develop road safety and traffic management applications. Secure vehicular communication, passenger comfort and infotainment are also objectives of ITS.
To generate novel ideas and development of novel technology, the project "Transport Research and Innovation Portal (TRIP)" [78] considers of transportation aiming to give an overview of research activities at European Union and National level. The European Commission also started a project in for "Transport Research and Innovation in Horizon 2020" [79] to generate ideas for growth of transportation, transport sustainability, seamless mobility and also viewing European Union (EU) as a leader on the globe. Car-2-Car is the project of Car-2Car Communication Consortium (C2C-CC) [80]. This project aims to contribute to the reduction of deaths in road accidents, reduce traffic congestion, improve efficiency and reduce the impact of the traffic on the environment.

Many projects are also running to develop prototypes of VANET for industry. Car-to-car cooperation [81] is a VANET project running in the Aqua-lab of Northwestern University. This project aims to provide information and entertainment to the passengers and automotive safety, and to reduce the impact of traffic on environment and smooth traffic flow. The project "Innovative Wireless Technologies for Industrial Automation (HiFlecs)" [82] in the University of Bremen, develops innovative wireless technologies for industrial real-time closed-loop applications. In the future industry, the wireless technologies allows to connect machinery and control units wirelessly. There are different challenges for future Industry 4.0 applications like low latency, highly reliability, deterministic, and secure communications. To meet these challenges, HiFlecs develop key technologies for an industrial wireless communication system with new functionality and features for real-time control applications. Intelligent System and Sensors [83] is the project of Auto21 for the development of control and monitoring of vehicle behavior, guidance, navigation, telematics, driving assistance and automation. Another funded project [84] of Auto 21 named "Vehicle Communications And Applications" at the Interlab of University of Sherbrook focuses on the development and testing of cost effective communication infrastructure, design of cooperative control strategies and their integration for vehicular communication applications. "Canadian Association of Road Safety and Professional (CARSP)" [85] is dedicated to enhance road safety by developing safety applications. Last, U.S. department of transportation is dealing with safety application where focused applications are emergency electronic brake lights, blind spot brakes, forward collision warnings, etc. It outlines new ITS Strategic Plan 2015-2019 [86] and provides a framework around with ITS Joint Program Office for research, development, and adoption activities to achieve goals. This plan is built around two key points i.e. priorities-realizing connected vehicle implementation and advancing automation. Furthermore, this plan includes program categories regarding connected 
TABLE V: Current Role of VANET in Logistics

\begin{tabular}{|l|l|l|}
\hline Article & Targeted Sub-task & Solution \\
\hline$[72] 73]$ & Enhancing port facilities & $\begin{array}{l}\text { Provide clustering solution to fulfill needs of port facilities like track and trace, security, } \\
\text { information sharing and visibility }\end{array}$ \\
\hline 74$]$ & $\begin{array}{l}\text { Visibility, control and connectivity across entire } \\
\text { supply chain }\end{array}$ & Provide enhances visibility and connectivity \\
\hline 75$]$ & $\begin{array}{l}\text { Monitoring and coordination of portside vehicular } \\
\text { traffic }\end{array}$ & $\begin{array}{l}\text { Reliable applications for monitoring and coordination, Efficient solution for information } \\
\text { sharing }\end{array}$ \\
\hline$[76]$ & $\begin{array}{l}\text { Logistic operations at intra and inter- } \\
\text { organizational level }\end{array}$ & $\begin{array}{l}\text { Build communication links between enter-prises and for many organizations around the } \\
\text { world }\end{array}$ \\
\hline
\end{tabular}

TABLE VI: Active Projects for Transportation

\begin{tabular}{|c|c|c|}
\hline Project & Purpose & Organization \\
\hline ITS $|77|$ & Road safety,traffic management, secure vehicular communication & European Commission \\
\hline TRIP 78] & Research activities for transportation & European Commission \\
\hline Horizon $2020[79$ & Ideas generation and growth sustainability of transport & European Commission \\
\hline $\mathrm{C} 2 \mathrm{C}[80]$ & $\begin{array}{l}\text { Fatalities reduction during road accidents,Improve efficiency,Reduce impact on environ- } \\
\text { ment }\end{array}$ & $\mathrm{C} 2 \mathrm{C}-\mathrm{CC}$ \\
\hline Car-to-Car cooperation $[81]$ & $\begin{array}{l}\text { Automotive safety, infotainment and entertainment for passengers, reduce traffic impact } \\
\text { on environment, smooth traffic flow }\end{array}$ & Aqua-lab,Northwestern University \\
\hline HiFlecs $[82]$ & To develop innovative wireless technologies for industry & University of Bremen \\
\hline Intelligent system and sensors $[83]$ & $\begin{array}{l}\text { Control and monitoring of vehicle behavior,vehicle guidance navigation and telematics, } \\
\text { driving assistance and automation }\end{array}$ & Auto21 \\
\hline $\begin{array}{l}\text { Vehicular communication and ap- } \\
\text { plications } 84\end{array}$ & $\begin{array}{l}\text { Development and testing of cost-effective communication infrastructure, design of coop- } \\
\text { erative control strategies }\end{array}$ & $\begin{array}{l}\text { Interlab, University of Sherbrook funded } \\
\text { by Auto } 21\end{array}$ \\
\hline CARSP [85] & Road safety & CARSP \\
\hline ITS 2015-2019 Strategic Plan 86$]$ & $\begin{array}{l}\text { Connected Vehicles, automation, emerging capabilities, enterprise data, inter-operability, } \\
\text { accelerating deployment }\end{array}$ & U.S. Department of Transportation \\
\hline
\end{tabular}

TABLE VII: Technologies Integration in Logistics and Transportation

\begin{tabular}{|c|c|c|c|}
\hline Technologies & Method & Purpose & Properties \\
\hline Multi-Agent System [29] 87 & Centralized and decentralized & Chain optimization, e-market place & Flexibility, simplicity, transaction and harmonization \\
\hline Online Technologies $[88]$ & Business collaboration & E-business & Availability, simplicity \\
\hline Robotics [20] 21] & Experisim, realism, inductivism & Automation & $\begin{array}{l}\text { Economical efficiency, engin performance and flex- } \\
\text { ibility }\end{array}$ \\
\hline $\begin{array}{l}\text { Wireless Sensor Networks } \\
\text { (WSN) 22] [23] }\end{array}$ & $\begin{array}{l}\text { Environmental monitoring, localization, } \\
\text { controlling }\end{array}$ & Detection, process control, monitoring & automation in information flow and control \\
\hline \begin{tabular}{ll|l|l} 
IoT & 58 & 62 & 63 \\
\end{tabular} & $\begin{array}{l}\text { Multilayered, centralized and decentral- } \\
\text { ized }\end{array}$ & $\begin{array}{l}\text { Synchronization, information flow, ma- } \\
\text { terial handling and safety and monitor- } \\
\text { ing }\end{array}$ & Real time synchronization, efficiency, flexibility \\
\hline VANET 24 25 & $\begin{array}{l}\text { Vehicles control communication and } \\
\text { road safety }\end{array}$ & $\begin{array}{l}\text { Controlled and efficient traffic manage- } \\
\text { ment, automation }\end{array}$ & $\begin{array}{l}\text { Low latency, high reliability, deterministic and se- } \\
\text { cure communication, cost-effective and flexibility }\end{array}$ \\
\hline
\end{tabular}

vehicles, automation, emerging capabilities, enterprise data, interoperability and accelerating deployment. Table $\mathrm{VI}$ gives the summary of the all presented projects where road safety or automotive safety are key targets. However, some projects are focusing on the monitoring and some projects are working to improve the traffic efficiency with minimal impact on the environment and cost effective communication infrastructure. From the current projects objectives, we conclude that companies are looking for low cost, automotive safety and monitoring solutions to support logistics and general transport applications with high reliability. Table VII summarizes the technologies integrated in logistics and transportation. Each technology aims to solve a problem by using specialized methods, and upon successful implementation and deployment, each system exhibits certain properties. As mentioned in the table, Multiagent System [29] [87] are used for chain optimization and to create e-market place through centralized and decentralized method. By applying this technique, the system becomes more simple, flexible and harmonized but less coordinated. Online technologies $[88]$ are used to maintain the system information for customers, re-sellers, business partners and to help in the online collaboration with partners, exchange of documents for contracts with customers, suppliers and also negotiation of contacts have become more easy. They provide a centralized and fast information management system, and also introduce e-business opportunities. Therefore, the advanced systems become more simple, flexible and also increase the accessibility and availability of data. Robotics [20] [21] is another technology, which renders the advanced system to be more flexible, efficient and cost effective. Robotics are used for automation of the system using different methodologies like expericism, realism and inductivism. For monitoring the environment, and controlling the process, WSN [22] [23] is applied. This technology allows for automation in information flow and control through environment monitoring, localizing the system, and controlling methods. To improve transportation efficiency, and for controlled and efficient traffic management automation, VANET technology [24] [25] [89] is imposed through communication methods. By using these wireless communication technologies, the transportation can become 
more secure, highly reliable and cost effective.

Currently, as mentioned in previous sections, VANET focuses on both safety [90] [91] and non-safety applications [92]. Non-safety applications are used to create commercial opportunities by increasing the number of equipped vehicles with on-board wireless devices. To make journey more pleasant for travelers, comfort and infotainment applications are being design and developed to provide information support and entertainment. Vehicular networks can also be employed to provide connectivity to catastrophe hit areas or remote rural communities lacking a conventional communication infrastructure to provide connectivity. Furthermore, Vehicular applications (for

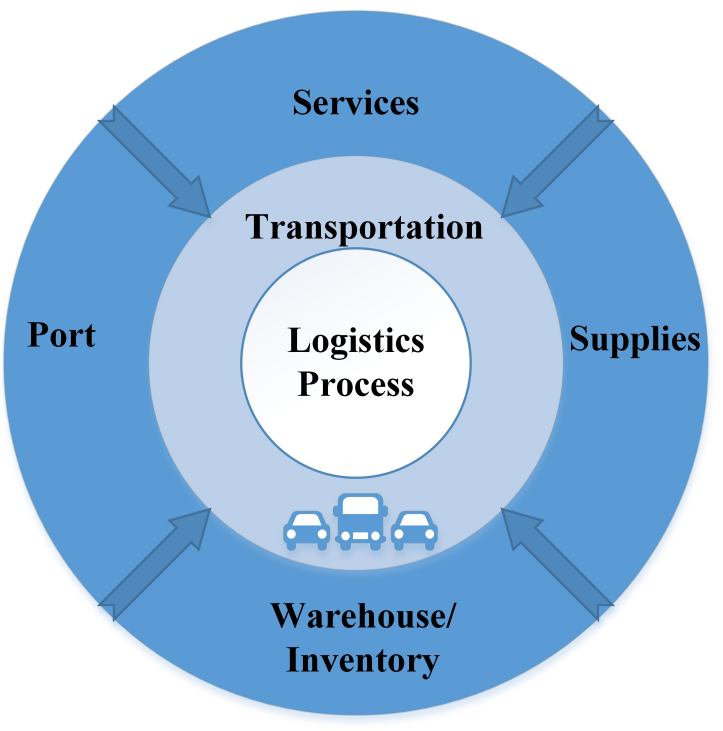

Fig. 4: VANET Integration in Logistics

example enhanced route guidance [93] and coordination by logistics providers, optimal scheduling of traffic light, and lane merging assistance by public coordinators) are intended to optimize routes [94], while also providing a reduction of gas emissions and fuel consumption. These applications are even more better when sensors are deployed for monitoring and controlling with VANET technology [95].

In logistics and transportation, many applications can be used like automatic vehicle detection or vehicle parking system for the logistic hot-spots (e.g sea port, warehouses etc.). It can also be used for the efficient traffic management for online delivery of logistics goods from production units to the distributed points or warehouses. Additionally, it allows automatic traffic control, re-routing the traffic in case of the traffic congestion [96] for improving just in time delivery and speed limit enforcement. Figure 4 shows the major four hot-spots of the logistics process where VANET technology can be used to maintain the information and logistics flow with the coordination of other technologies where transportation is the key factor that links industries to customers and consumers. We already know that for automation in manufacturing we use robotics and to maintain database of products and information online technologies and sensors are already deployed on different production units. By integrating these deployed technologies with VANET, we can improve efficiency in automation in terms of information flow and control. Considering Figure 4 within logistic processes the key goals are automation, monitoring, process control, chain optimization and information base, and currently multiple technologies are being used in each hotpots to achieve goals. In supplies, the need of facilities include monitoring, controlling, information and management, where sensors, WSN and online technologies are being used to fulfill their requirement. In warehouse and inventory management, there are different challenges like pelleting, packaging, storing, etc. In this scenario, handling, controlling, coordination and managing information are important tasks to complete, where robotics, WiFi technologies, sensors, database technologies or online technologies are being used for efficient handling. In ports, the challenges are to load and unload in optimal time, handling and information management. Here robotics, WSN, Multi-agent Systems and VANET are being used to cope with them. At the service level, companies are looking for solutions to ease the processes of purchasing, shipping, monitoring, tracking and controlling. They are using online technologies, multi-agent and sensors to deal with those processes. We observed in this case study, VANET has the potential for not only to inter-link these hotspots, but also to improve each unit. Hence, efficiency in delivery can improve economic factors for industries, and improve service level for customers and consumers while managing the freight transportation by providing best routing information, alerts for traffic jam or rerouting for congestion.

\section{CONClusions AND Future WORK}

VANET is the one of the enabling technology in ITS that is used for road safety, traffic management and logistics applications. With the objective of the technologies and VANET integration in logistics and transportation, an overview of all technologies with logistics functions have been derived and summarized. Different technologies like multi-agent systems, online technologies, robotics, wireless sensor networks have been used to fast the process of manufacturing and to make the deliveries just in time over the last few years. We highlighted different challenges for each technology to provide flexible and effective solutions in terms of time and cost. We discussed VANET as key technology in logistics and transportation regarding challenges to cope with the mobility and short contact duration, where it is observed that VANET has potential to provide flexible and cost-effective solutions for logistics and transportation. It also has capability to make bridge to interlink hotspots of logistics process. For the deployment of this technology along attractive applications, a number of projects are running. This article also gave an overview of projects focusing respective extensions.

\section{REFERENCES}

[1] J. Eckhardt and J. Rantala, "The Role of Intelligent Logistics Centres in a Multimodal and Cost-effective Transport System," Procedia-Social and Behavioral Sciences, Elsevier, vol. 48, pp. 612-621, 2012.

[2] E. Comission. (2015) Mobility and Transport. [Online]. Available: http://ec.europa.eu/transport/themes/index_en.htm

[3] D. Eckhoff, N. Sofra, and R. German, "A Performance Study of Cooperative Awareness in ETSI ITS G5 and IEEE WAVE," in IEEE 10th Annual Conference on Wireless On-demand Network Systems and Services (WONS), 2013, 2013, pp. 196-200. 
[4] W.-F. Alliance, "Wi-Fi Protected Access: Strong, Standards-based, Interoperable Security for Todays Wi-Fi Networks," White paper, University of Cape Town, 2003.

[5] E. Dahlman, S. Parkvall, J. Skold, and P. Beming, $3 G$ evolution: HSPA and LTE for mobile broadband. Linacre House, Jordan Hill, Oxford, OX28DP: Second Edition, Academic press, 2010.

[6] S. Sesia, I. Toufik, and M. Baker, LTE: the UMTS long term evolution. The Atrium, Southern Gate, Chichester, West Sussex, PO19 8SQ, United Kingdom: Wiley Online Library, 2009.

[7] K. A. Khaliq, J. Pannek, and A. Qayyum, "Methodology for Development of Logistics Information and Safety System Using VANET," Springer Lecture Notes on Logistics Proceedings of the 5th International Conference on Dynamics in Logistics LDIC, pp. 185-195, 2016.

[8] M. Amadeo, C. Campolo, and A. Molinaro, "Enhancing IEEE 802.11p/WAVE to Provide Infotainment Applications in VANETs," Ad Hoc Networks, vol. 10, no. 2, pp. 253-269, 2012.

[9] R. G. Kasilingam, "Logistics and Transportation," Great Britain: Kluwer Academic Publishers, 1998.

[10] C. L. Weber and H. S. Matthews, "Food-miles and the Relative Climate Impacts of Food Choices in the United States," Environmental science \& technology, vol. 42, no. 10, pp. 3508-3513, 2008.

[11] E. Ros, "Shelter Container Fit for Habitation with Extendible Inner Volume," Aug. 24 1993, uS Patent 5,237,784.

[12] S. Tayur, R. Ganeshan, and M. Magazine, Quantitative Models for Supply Chain Management. New York: Springer Science \& Business Media, 2012, vol. 17.

[13] C. Gimenez, T. van der Vaart, and D. Pieter van Donk, "Supply Chain Integration and Performance: The Moderating Effect of Supply Complexity," International Journal of Operations \& Production Management, vol. 32, no. 5, pp. 583-610, 2012.

[14] D. Prajogo and J. Olhager, "Supply Chain Integration and Performance: The Effects of Long-term Relationships, Information Technology and Sharing, and Logistics Integration," International Journal of Production Economics, Elsevier, vol. 135, no. 1, pp. 514-522, 2012.

[15] H. Stadtler, "Supply Chain Management: An Overview," in Supply Chain Management and Advanced Planning, Springer, 2015, pp. 3-28.

[16] A. P. C. Postelnicu and A. P. D.-C. Dabija, "Transfer and Diffusion of New Technologies Within the Supply Chain of Multinational Companies with Operations in RomaniaA Contemporary Approach," in Geopolitics, Development, and National Security, Springer, 2015, pp. 53-66.

[17] A. Musa, A. Gunasekaran, Y. Yusuf, and A. Abdelazim, "Embedded Devices for Supply Chain Applications: Towards Hardware Integration of Disparate Technologies," Expert Systems with Applications, Elsevier, vol. 41, no. 1, pp. 137-155, 2014.

[18] A. Musa, A. Gunasekaran, and Y. Yusuf, "Supply Chain Product Visibility: Methods, Systems and Impacts," Expert Systems with Applications, Elsevier, vol. 41, no. 1, pp. 176-194, 2014.

[19] S.-J. Chuu, "An Investment Evaluation of Supply Chain RFID Technologies: A Group Decision-making Model with Multiple Information Sources," Knowledge-Based Systems, Elsevier, vol. 66, pp. 210-220, 2014.

[20] W. Echelmeyer, A. Kirchheim, and E. Wellbrock, "Robotics-logistics: Challenges for automation of logistic processes," in IEEE International Conference on Automation and Logistics (ICAL), 2008, pp. 2099-2103.

[21] W. Echelmeyer, A. Kirchheim, A. J. Lilienthal, H. Akbiyik, and M. Bonini, "Performance Indicators for Robotics Systems in Logistics Applications," in IROS Workshop on Metrics and Methodologies for Autonomous Robot Teams in Logistics (MMARTLOG), 2011, p. 55.

[22] T.-H. Shin, S.-W. Yoon, and S. Chin, "A Construction Supply Chain Management Process with RFID/WSN-based Logistics Equipment," Journal of Construction Engineering and Project Management, vol. 2, no. 4, pp. 11-19, 2012.

[23] L. Evers, M. J. Bijl, M. Marin-Perianu, R. Marin-Perianu, and P. J. Havinga, "Wireless Sensor Networks and Beyond: A Case Study on Transport and Logistics," 2005.

[24] A. E. C. Mondragon and E. S. C. Mondragon, "Smart Grid and Wireless Vehicular Networks for Seaport Logistics Operations," in 19th ITS World Congress, 2012.
[25] S. Eichler, C. Schroth, and J. Eberspächer, "Car-to-Car Communication," in VDE-Kongress. VDE VERLAG GmbH, 2006.

[26] D. Simchi-Levi, X. Chen, and J. Bramel, The Logic of Logistics: Theory, Algorithms, and Applications for Logistics Management, New York, Heidelberg, Dortrecht, London, 2013.

[27] A. Chiarini and A. Douglas, "The Impact of Logistics Solutions on Customer Satisfaction: An Exploratory Qualitative Study of Sanufacturing Companies," Sinergie Italian Journal of Management, pp. 255-270, 2015.

[28] W. W. Powell and K. Snellman, "The knowledge economy," JSTOR journal of Annual Review of Sociology, pp. 199-220, 2004.

[29] E. Mangina and I. P. Vlachos, "The Changing Role of Information Technology in Food and Beverage Logistics Management: Beverage Network Optimisation Using Intelligent Agent Technology," Journal of Food Engineering, Elsevier, vol. 70, no. 3, pp. 403-420, 2005.

[30] J. Stock, "International Journal of Physical Distribution \& Logistics Management," Marketing Intelligence \& Planning, vol. 10, no. 7, pp. $12-15,1992$.

[31] J. R. Stock, "Development and Implementation of Reverse Logistics Programs," in Annual Conference Proceedings, Council of Logistics Management, 1998.

[32] L.-H. Shih, "Reverse Logistics System Planning for Recycling Electrical Appliances and Computers in Taiwan," Resources, Conservation and Recycling, Elsevier, vol. 32, no. 1, pp. 55-72, 2001.

[33] E. Behmanesh and J. Pannek, "A Closed Loop Supply Chain Model with Flexible Delivery Path and Extended Random Path-based Direct Encoding," 2015.

[34] M. G. Avci and H. Selim, "A multi-agent system model for supply chains with lateral preventive transshipments: Application in a multinational automotive supply chain," Elsevier Journal of Computers in Industry, vol. 82, pp. 28-39, 2016.

[35] H. K. Chow, K. L. Choy, and W. Lee, "A dynamic logistics process knowledge-based system-An RFID multi-agent approach," KnowledgeBased Systems, Elsevier, vol. 20, no. 4, pp. 357-372, 2007.

[36] W. Ying and S. Dayong, "Multi-agent framework for third party logistics in E-commerce," Journal of Expert Systems with Applications, Elsevier, vol. 29, no. 2, pp. 431-436, 2005.

[37] D. Perugini, S. Wark, A. Zschorn, D. Lambert, L. Sterling, A. Pearce et al., "Agents in Logistics Planning-experiences with the Coalition Agents Experiment Project," in Proceedings of workshop at the Second International Joint Conference on Autonomous Agents and Multiagent Systems (AAMAS 2003). Melburne, Australia, 2003.

[38] K. Zhu and A. Bos, "Agent-based design of intermodal freight transportation systems," in NECTAR Conference, 1999.

[39] B. Burmeister, A. Haddadi, and G. Matylis, "Application of multiagent systems in traffic and transportation," IEEE Proceedings-Software Engineering, vol. 144, no. 1, pp. 51-60, 1997.

[40] J. L. Adler and V. J. Blue, "A cooperative multi-agent transportation management and route guidance system," Transportation Research Part C: Emerging Technologies, vol. 10, no. 5, pp. 433-454, 2002.

[41] I. J. Timm, P.-O. Woelk, P. Knirsch, H.-K. Tönshoff, and O. Herzog, "Flexible Mass Customisation: Managing Its Information Logistics Using Adaptive Cooperative Multi-agent Systems," in Developments in Logistics and Supply Chain Management. Springer, 2016, pp. 203-211.

[42] O. N. Granichin, P. Skobelev, A. Lada, I. Mayorov, and A. Tsarev, "Comparing Adaptive and Non-adaptive Models of Cargo Transportation in Multi-agent System for Real Time Truck Scheduling," in IJCCI, 2012, pp. 282-285.

[43] T. Sprodowski and J. Pannek, "Stability of distributed MPC in an intersection scenario," in Journal of Physics: Conference Series, vol. 659, no. 1. IOP Publishing, 2015, p. 012049.

[44] F. Arendt, O. Klein, and K. Barwig, "Intelligent Control of Freight Services on the Basis of Autonomous Multi-agent Transport Coordination," in Springer:Logistics and Supply Chain Innovation, 2016, pp. 313-324.

[45] N. Anand, R. van Duin, and L. Tavasszy, "Ontology-based Multi-agent System for Urban Freight Transportation," International Journal of Urban Sciences, vol. 18, no. 2, pp. 133-153, 2014.

[46] T. Bock, "Construction Robotics," Springer Journal of Autonomous Robots, vol. 22, no. 3, pp. 201-209, 2007. 
[47] U. Karras, D. Pensky, and O. Rojas, "Mobile Robotics in Education and Research of Logistics," in Workshop on Metrics and Methodologies for Autonomous Robot Teams in Logistics (IROS 2011), vol. 72, 2011.

[48] M. Bliesener, C. Weber, K. Kling, U. Karras, and D. Zitzmann, "Festo Robotino Manual," Denkendorf: Festo Didactic GmbH \& Co. KG, 2007.

[49] H. Weinert and D. Pensky, "Mobile Robotics in Education and Student Engineering Competitions," in IEEE AFRICON, 2011, 2011, pp. 1-5.

[50] T. Niemueller, G. Lakemeyer, and A. Ferrein, "The Robocup Logistics League as a Benchmark for Planning In Robotics," in WS on Planning and Robotics (PlanRob) at Int. Conf. on Aut. Planning and Scheduling (ICAPS), 2015

[51] G. Q. Huang, M. Z. Chen, and J. Pan, "Robotics in Ecommerce Logistics," HKIE Transactions, vol. 22, no. 2, pp. 68-77, 2015.

[52] S. Low, J. Goh, S. K. Yeung, and I. Chia, "Building IT Capabilities to Deploy Large-Scale Synchronous Online Technology in Teaching and Learning," in International Conference on HCI in Business, Government and Organizations, Springer, 2016, pp. 531-544.

[53] R. Smith, G. Deitz, M. B. Royne, J. D. Hansen, M. Grünhagen, and C. Witte, "Cross-cultural Examination of Online Shopping Behavior: A Comparison of Norway, Germany, and the United States," Journal of Business Research, vol. 66, no. 3, pp. 328-335, 2013.

[54] M. Koufaris, "Applying the Technology Acceptance Model and Flow Theory to Online Consumer Behavior," Information systems research, vol. 13, no. 2, pp. 205-223, 2002.

[55] D. Bowie, A. Paraskevas, and A. Mariussen, "Technology-Driven Online Marketing Performance Measurement: Lessons from Affiliate Marketing," International Journal of Online Marketing (IJOM), vol. 4, no. 4, pp. 1-16, 2014.

[56] A. R. Ashraf, N. Thongpapanl, and S. Auh, "The Application of the Technology Acceptance Model under Different Cultural Contexts: The Case of Online Shopping Adoption," Journal of International Marketing, vol. 22, no. 3, pp. 68-93, 2014.

[57] T. Escobar-Rodríguez and E. Carvajal-Trujillo, "Online Purchasing Tickets for Low Cost Carriers: An Application of the Unified Theory of Acceptance and Use of Technology (UTAUT) Model," Tourism Management, vol. 43, pp. 70-88, 2014.

[58] T. Qu, S. Lei, Z. Wang, D. Nie, X. Chen, and G. Q. Huang, "Iot-based real-time production logistics synchronization system under smart cloud manufacturing," The International Journal of Advanced Manufacturing Technology, vol. 84, no. 1-4, pp. 147-164, 2016.

[59] A. P. Hsu, W. Lee, A. J. Trappey, C. V. Trappey, and A.-C. Chang, "Using system dynamics analysis for performance evaluation of iot enabled one-stop logistic services," in Systems, Man, and Cybernetics (SMC), 2015 IEEE International Conference on. IEEE, 2015, pp. 1291-1296.

[60] W. He, G. Yan, and L. Da Xu, "Developing vehicular data cloud services in the iot environment," IEEE Transactions on Industrial Informatics, vol. 10, no. 2, pp. 1587-1595, 2014.

[61] C. Verdouw, R. Robbemond, T. Verwaart, J. Wolfert, and A. Beulens, "A reference architecture for iot-based logistic information systems in agri-food supply chains," Enterprise Information Systems, pp. 1-25, 2015.

[62] M. Roidl, J. Emmerich, A. Riesner, M. Masoudinejad, D. Kaulbars, C. Ide, C. Wietfeld, and M. Ten Hompel, "Performance availability evaluation of smart devices in materials handling systems," in IEEE/CIC International Conference on Communications in ChinaWorkshops (CIC/ICCC) (2014), 2014, pp. 6-10.

[63] H. D. Zhao, H. Z. Wang, G. N. Liu, C. Li, and M. H. Zhao, "The application of internet of things (iot) technology in the safety monitoring system for hoisting machines," in Applied Mechanics and Materials, vol. 209. Trans Tech Publ, 2012, pp. 2142-2145.

[64] Z. Alazawi, S. Altowaijri, R. Mehmood, and M. B. Abdljabar, "Intelligent Disaster Management System Based on Cloud-enabled Vehicular Networks," in ITS Telecommunications (ITST), 2011 11th International Conference on. IEEE, 2011, pp. 361-368.

[65] J. Sun, X. Zhu, C. Zhang, and Y. Fang, "RescueMe: Location-based Secure and Dependable VANETs for Disaster Rescue," Selected Areas in Communications, IEEE Journal on, vol. 29, no. 3, pp. 659-669, 2011.

[66] N. R. Siddiqui, K. A. Khaliq, and J. Pannek, "VANET Security Analysis on the Basis of Attacks in Authentication," Springer Lecture Notes on
Logistics Proceedings of the 5th International Conference on Dynamics in Logistics, pp. 491-502, 2016.

[67] A. Rasheed, H. Zia, F. Hashmi, U. Hadi, W. Naim, and S. Ajmal, "Fleet \& convoy management using VANET," Journal of Computer Networks, vol. 1, no. 1, pp. 1-9, 2013.

[68] M. S. Akbar, K. A. Khaliq, and A. Qayyum, "Vehicular MAC Protocol Data Unit (V-MPDU): IEEE 802.11p MAC Protocol Extension to Support Bandwidth Hungry Applications," in Vehicular Ad-hoc Networks for Smart Cities, Springer, 2015, pp. 31-39.

[69] K. A. Khaliq, J. Pannek, and A. Qayyum, "Suitability of IEEE $802.11 \mathrm{ac} / \mathrm{n} / \mathrm{p}$ for Bandwidth Hungry and Infotainment Applications for Cities," IEEE SAI Intelligent Systems (IntelliSys 2016), pp. 499-509, 2016.

[70] M. S. Akbar, M. S. Khan, K. A. Khaliq, A. Qayyum, and M. Yousaf, "Evaluation of IEEE 802.11n for Multimedia Application in VANET," Procedia Computer Science, vol. 32, pp. 953-958, 2014.

[71] M. H. Arbabi and M. Weigle, "Using Vehicular Networks to Collect Common Traffic Data," in Proceedings of the sixth ACM international workshop on VehiculAr InterNETworking, ACM, 2009, pp. 117-118.

[72] A. E. C. Mondragon, E. S. C. Mondragon, and C. E. C. Mondragon, "Clustering DSRC-Based Networks for Logistics Operations in Ports," in 17th ITS World Congress, 2010.

[73] C. S. Lalwani et al., "Wireless Vehicular Networks to Support Road Haulage and Port Operations in a Multimodal Logistics Environment," in IEEE/INFORMS International Conference on Service Operations, Logistics and Informatics (SOLI'09), 2009, pp. 62-67.

[74] A. E. C. Mondragon, C. S. Lalwani, E. S. C. Mondragon, and C. E. C. Mondragon, "Facilitating Multimodal Logistics and Enabling Information Systems Connectivity Through Wireless Vehicular Networks," Elsevier International Journal of Production Economics, vol. 122, no. 1, pp. 229-240, 2009.

[75] A. E. C. Mondragon, E. S. C. Mondragon, C. E. C. Mondragon, and F. Mungau, "Estimating the Performance of Intelligent Transport Systems Wireless Services for Multimodal Logistics Applications," Elsevier Expert Systems with Applications, vol. 39, no. 4, pp. 39393949, 2012.

[76] A. E. C. Mondragon, E. S. C. Mondragon, and C. E. C. Mondragon, "Innovative Information and Communication Technology for Logistics: The Case of Road Transportation Feeding Port Operations and Direct Short Range Communication Technology," in Springer Supply Chain Management and Knowledge Management, 2009, pp. 254-268.

[77] European Comission. (2015) Intelligent Transport System (ITS). [Online]. Available: http://ec.europa.eu/transport/themes/its/index_en. htm

[78] —. (2015) Transport Research and Innovation Portal (TRIP). [Online]. Available: http://ec.europa.eu/transport/themes/research/trip_ en.htm

[79] —. (2015) Transport Research and Innovation in Horizon 2020. [Online]. Available: http://ec.europa.eu/transport/themes/research/ horizon2020 en.htm

[80] (2015) Car-2-Car Communication Consortium (C2C-CC). [Online]. Available: https://www.car-2-car.org/index.php?id=5

[81] Northwestern University. (2015) Car-to-Car Cooperation. [Online]. Available: http://www.aqualab.cs.northwestern.edu/projects/ 111-c3-car-to-car-cooperation-for-vehicular-ad-hoc-networks

[82] Universität Bremen, Institut für Telekommunikation und Hochfrequenztechnik. (2015) Innovative wireless technologies for industrial automation (HiFlecs). [Online]. Available: http: //www.ant.uni-bremen.de/en/projects/hiflecs/

[83] Auto21. (2015) Intelligent Systems and Sensors. [Online]. Available: https://auto21.ca/en/subcontent?page $=a e 2600$

[84] Interlab, University of Sherbrook, Canada. (2015) Vehicle Communications And Applications. [Online]. Available: http: //www.gel.usherbrooke.ca/interlab/index.php?page=projects

[85] (2015) Canadian Association of Road Safety Professionals (CARSP). [Online]. Available: http://www.carsp.ca/

[86] U. D. of Transportation. (2016) ITS Strategic Plan 215-16 . [Online] Available: http://www.its.dot.gov/research_areas/strategicplan2015.htm 
[87] M. Giannakis and M. Louis, "A Multi-agent Based Framework for Supply Chain Risk Management," Journal of Purchasing and Supply Management, Elsevier, vol. 17, no. 1, pp. 23-31, 2011.

[88] F. Lai, D. Li, Q. Wang, and X. Zhao, "The information technology capability of third-party logistics providers: a resource-based view and empirical evidence from China," Journal of Supply Chain Management, Wiley Online Library, vol. 44, no. 3, pp. 22-38, 2008.

[89] X. Yan, P. Yi, D. Zhu, and L. Fu, "ICTIS 2013: Improving Multimodal Transportation Systems-Information, Safety, and Integration." American Society of Civil Engineers, 2013.

[90] K. A. Hafeez, L. Zhao, Z. Liao, and B. N.-W. Ma, "Impact of mobility on vanets' safety applications," in IEEE Global Telecommunications Conference (GLOBECOM 2010), 2010, pp. 1-5.

[91] M. S. Akbar, A. Qayyum, and K. A. Khaliq, "Information Delivery Improvement for Safety Applications in VANET by Minimizing Rayleigh and Rician Fading Effect," in Vehicular Ad-hoc Networks for Smart Cities, Springer, 2015, pp. 85-92.

[92] M. Ahyar and R. F. Sari, "Performance Evaluation of Multi-Channel Operation For Safety And Non-Safety Application On Vehicular Ad Hoc Network IEEE 1609.4," International Journal of SimulationSystems, Science and Technology, vol. 14, no. 1, pp. 16-22, 2013.

[93] M. Khanjary and S. M. Hashemi, "Route Guidance Systems: Review and Classification," in Proceedings of the 6th Euro American Conference on Telematics and Information Systems, ACM, 2012, pp. 269-275.

[94] K. Collins and G.-M. Muntean, "A Vehicle Route Management Solution Enabled by Wireless Vehicular Networks," in IEEE INFOCOM Workshops, 2008, pp. 1-6.

[95] M. Ferreira and P. M. d'Orey, "On the Impact of Virtual Traffic Lights on Carbon Emissions Mitigation," IEEE Transactions on Intelligent Transportation Systems, vol. 13, no. 1, pp. 284-295, 2012.

[96] S. Dornbush and A. Joshi, "Street Smart Traffic: Discovering and Disseminating Automobile Congestion Using VANET's," in IEEE 65th Vehicular Technology Conference (VTC2007-Spring), 2007, pp. 11-15. 